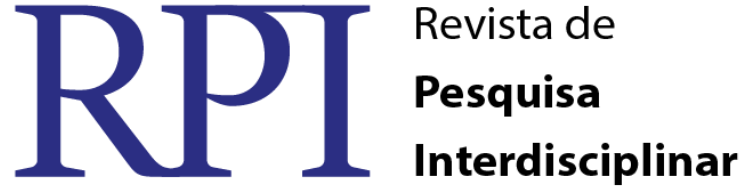

\section{CONTRIBUIÇÕES PARA DESMISTIFICAÇÃO DA EDUCAÇÃO A DISTÂNCIA}

\author{
Manoel Vanderson Vieira Batista ${ }^{1}$ \\ Carlos Davidson Pinheiro ${ }^{1}$
}

\begin{abstract}
RESUMO
O presente artigo trata-se de uma revisão integrativa da literatura que aborda a Educação a Distância na suas várias vertentes visando contribuir de maneira efetiva e significativa para a desmistificação dessa modalidade de ensino tão pragmatizada ao longo do tempo, discutindo características envolvendo EAD, suas fases, importância e desafios encontrados nesse percurso, delineando essa discussão através de aportes teóricos. Teve-se uma revisão ampla e abrangente da literatura visando sintetizar resultados obtidos em pesquisas e trabalhos sobre o assunto em questão, de forma sistemática. Este tipo de revisão proporciona informações mais amplas acerca do assunto. Foi verificado os conceitos e relações substanciais para tal discussão, levando a inferir que para o bom funcionamento dessa modalidade de ensino tem que ser garantido bons materiais de estudo, uma plataforma que permita interação efetiva entre todos os participantes, bem como profissionais qualificados (tutores) para esse trabalho tão importante, tendo em vista que eles incentivarão seus alunos a serem autônomos e disciplinados para o estudo.
\end{abstract}

Palavras-chave: Tecnologias da Informação e Comunicação; Educação a distância; Modalidade de ensino.

\section{CONTRIBUTIONS FOR THE DISMISSAL OF DISTANCE EDUCATION}

\begin{abstract}
This article is an integrative review of the literature that addresses Distance Education in its various aspects in order to contribute in an effective and meaningful way to the demystification of this modality of teaching so pragmatized over time, discussing characteristics involving EAD, its phases , importance and challenges found in this course, outlining this discussion through theoretical contributions. There was a broad and comprehensive review of the literature in order to synthesize results obtained in researches and works on the subject in question, in a systematic way. This type of review provides more extensive information about the subject. It was verified the concepts and substantial relations for such a discussion, leading to the conclusion that for the good functioning of this teaching modality, good study materials must be guaranteed, a platform that allows effective interaction among all the participants, as well as qualified professionals (tutors) for this important work, given that they will encourage their students to be autonomous and disciplined for the study.
\end{abstract}

Keywords: Information and Communication Technologies; Distance education; Teaching modality.

\section{INTRODUÇÃO}

\footnotetext{
${ }^{1}$ Universidade Federal de Campina Grande - UFCG.
} 
Partindo do ponto de vista de que as Tecnologias da Informação e Comunicação (TIC) são todas as tecnologias que interferem e mediam os processos informacionais e comunicativos da sociedade em que vivemos, pode-se afirmar que elas exercem um papel importantíssimo, não só no campo da comunicação, mas também na maneira do homem aprender, de ensinar e, sobretudo, de viver.

Pode-se perceber uma evolução significativa no processo de inclusão digital em se tratando da informática educativa que, a priori, prima pelo ensino da tecnologia no âmbito da escola, onde o aprendente fazia uso das ferramentas tecnológicas para facilitar e dinamizar a construção do seu conhecimento e o professor, qual mediador, explora alguns recursos tecnológicos disponíveis na escola para ampliar as possibilidades do público alvo.

Tais possibilidades tecnológicas proporcionam à sociedade grandes transformações que perpassam por todos os setores, chegando, inclusive, no educacional. As instituições de ensino estão tentando absorver e se apropriar dessas mudanças, principalmente, através da figura do professor que precisa lidar com essa revolução, tirando proveito dela para potencializar o processo de ensino e aprendizagem, redesenhando assim, muitas questões educacionais, especialmente o aprender e o ensinar.

$\mathrm{O}$ acesso às novas tecnologias de informação e comunicação (TICs), bem como o avanço da infraestrutura tecnológica que proporcionou um aumento significativo da EAD, oportunizou através desta, o acesso a educação em diversos níveis, desde um curso de capacitação a uma formação acadêmica e/ou continuada.

\section{METODOLOGIA}

$\mathrm{Na}$ realização deste trabalho, foram feitas revisões integrativas das literaturas a respeito do assunto estudado, utilizando para tanto, artigos, trabalhos científicos de diferentes autores, pesquisados em portais de busca por periódicos, Periódicos da CAPES, Google Acadêmico, SciELO, BDTD - Biblioteca Digital Brasileira de Teses e Dissertações, que alicerçam e dão credibilidade as ideias aqui expostas. Para delinear a pesquisa, não se seguiu critérios datais de publicação das obras analisadas, levando em consideração que toda escrita científica, seja ela mais antiga ou não, tem relevância para o aporte teórico, prático e metodológico na construção de novos conhecimentos, hipóteses, conceitos e teorias, a fim de desenvolver o conhecimento científico que sempre é mensurável e mutável. Após a seleção dos artigos e/ou matérias, os mesmos foram analisados conforme sua contribuição para a 
pesquisa, confrontando ideias dos autores, que serviu de subsídio, com suas considerações importantes, para o engrandecimento da temática em questão.

A realização de uma revisão integrativa de literatura visa sintetizar resultados obtidos em pesquisas e trabalhos sobre um determinado tema, de forma sistemática e abrangente. Este tipo de revisão proporciona informações mais amplas acerca de um assunto/problema, e pode ser constituída para diversas finalidades, como, por exemplo, ser direcionada para a definição de conceitos, revisão de teorias ou investigação metodológica dos estudos de uma temática em particular (ERCOLE et al, 2014).

Souza (et al, 2010) diz que a revisão integrativa direciona a prática fundamentando-se em conhecimento científico, adequando vários dados de delineamento de pesquisa, por meio da inclusão de uma sistemática e rigorosa abordagem do processo, principalmente, através da análise de dados, o que pode resultar na diminuição de vieses e erros para o trabalho.

\section{RESULTADOS E DISCUSSÃO}

\section{EAD e suas premissas}

O método de ensino à distância vem crescendo numa velocidade nunca antes vista, mas tudo começou antes mesmo da expansão das TICs, quando os curso eram por correspondência (BALBINOT et al, 2010). Segundo Rosin (2010) os avanços tecnológicos e a rápida difusão das informações abriram campo para a ampliação da educação numa perspectiva formativa e continuada, mas é importante lembrar que a Educação a Distância não é uma nova modalidade de ensino, e sim os meios que ela acontece, sendo melhor explorada por todos que se propuserem a aprender ou ensinar algo de forma mais aberta e flexível.

Ainda segundo Rosin (2010), existiram muitos projetos educacionais no Brasil com a utilização de rádio, TV e correios durante muito tempo, tendo em alguns deles apenas o aperfeiçoamento que garantiu a sua continuidade e outros sua extinção.

Essa autora (ROSIN, 2010) traz ainda em seu trabalho uma linha do tempo sobre os principais projetos e acontecimentos relacionados à Educação a Distância em nosso país, tendo como destaque: Cursos de formação profissional por correspondência de 1904 a 1950 pelas Escolas Internacionais que era uma instituição Norte Americana, tendo como objetivo a empregabilidade nos setores de comércio e serviços; A rádio Sociedade do Rio de Janeiro em 
1923 promovendo a educação popular e em 1924 foi criado o Serviço de Radiodifusão Educativa do Ministério da Educação regulamentando as transmissões dos programas educativos; O Instituto Rádio Técnico Monitor (1939) com seus cursos por correspondência na área de eletrônica e radiotécnica; O instituto Universal Brasileiro (1941), o maior difusor de cursos profissionalizantes a distância no país; O SENAC (1946), sendo criado através do mesmo a Universidade do Ar (iniciando em1947 e findando em 1961), continuando o SENAC com suas atividades em EAD até os dias atuais; Em 1965 iniciou-se alguns projetos como o Projeto Minerva, o Projeto Saci e o Telecurso.

Ainda segundo Rosin (2010) foi instituída em 1971 a ABT (Associação Brasileira de Teleducação) e hoje se denomina Associação Brasileira de Tecnologia Educacional, sendo em 1981 reconhecido pelo Conselho Federal de Educação para cursos de pós-graduação lato senso, ministrados por correspondência em parceria com a CAPES - Coordenação de Aperfeiçoamento de Pessoas de Nível Superior; Em 1984 foi criado o Projeto Ipê para a capacitação de professores de $1^{\circ}$ e $2^{\circ}$ Graus por meio de programas da TV Cultura, sendo esse um precursor da TV Escola; Iniciou-se em 1989 a utilização das primeiras formas de comunicação em rede e com maior frequência as teleconferências via satélite; Em 1994 e 1995 respectivamente teve-se as primeiras experiências de EAD em cursos de graduação (UFSC) e na (UFMT); Em 1995 foi fundada a Associação Brasileira de Educação a Distância, promovendo a difusão uso da internet nas IES - Instituições de Ensino Superior; Oficialização e reconhecimento nacional pela LDB - Lei de Diretrizes e Bases em 1996, bem como a criação da Secretaria de educação a Distância (SEED); E em 1998 normatização, através de decretos e portarias, da EAD, sendo em 1999 o aumento no uso das NTIC's (Novas Tecnologias da Informação e Comunicação), bem como o credenciamento das instituições para atuação em EAD.

A Educação a Distância nasceu numa época que tinha poucos meios de ser propagada, em que os principais que davam suporte para que ela acontecesse eram os correios e o rádio, e com o avanço tecnológico ela vem ganhando cada vez mais espaço, tendo como aliada a informática, com seus softwares educativos, Ambientes Virtuais de Aprendizagens (AVA's) entre outros tantos que auxilia no funcionamento dessa modalidade de ensino (PIRES et al, 2017).

Toda via, a dinâmica da Educação a Distancia é diferenciada da tradicional, onde se tem um espaço físico e um professor para lhe auxiliar presencialmente a qualquer tempo dentro daquela sala. Essa modalidade requer, e de certa forma incentiva, a autonomia do 
estudante, a busca de materiais alternativos daqueles contemplados nas ementas das disciplinas, domínio das ferramentas ou plataformas dos cursos, relação com a turma através dos chats e fóruns, bem como com o tutor, e organização de horários para estudo. Ela permite uma interação maior entra as pessoas da área afim e também de outras áreas do conhecimento, facilitando uma transversalidade de conteúdos, característica importante para a práxis educativa (ANDRADE, 2018).

Dessa forma, atualmente nos deparamos com diversos cursos em EAD, tanto de iniciativa pública como privada, desde uma capacitação, uma graduação e até mesmo uma pós-graduação, sendo considerada hoje uma modalidade de educação indispensável devido a sua abrangência e sua flexibilidades de horários e locais.

Legalmente ela está embasada na Lei de Diretrizes e Bases No 9.394 de 1996, que regulamenta a educação a distância desde a educação básica, formação inicial e continuada / capacitação de profissionais de magistério, e em seu Art. 80, traz o seguinte:

Art. 80. O Poder Público incentivará o desenvolvimento e a veiculação de programas de ensino a distância, em todos os níveis e modalidades de ensino, e de educação continuada.

$\S 1^{\circ}$ A educação a distância, organizada com abertura e regime especiais, será oferecida por instituições especificamente credenciadas pela União.

$\S 2^{\circ}$ A União regulamentará os requisitos para a realização de exames e registro de diploma relativos a cursos de educação a distância.

$\S 3^{\circ}$ As normas para produção, controle e avaliação de programas de educação a distância e a autorização para sua implementação, caberão aos respectivos sistemas de ensino, podendo haver cooperação e integração entre os diferentes sistemas.

$\S 4^{\circ}$ A educação a distância gozará de tratamento diferenciado, que incluirá:

I - custos de transmissão reduzidos em canais comerciais de radiodifusão sonora e de sons e imagens;

I - custos de transmissão reduzidos em canais comerciais de radiodifusão sonora e de sons e imagens e em outros meios de comunicação que sejam explorados mediante autorização, concessão ou permissão do poder público; $\quad$ (Redação dada pela Lei $n^{\circ} 12.603$, de 2012)

II - concessão de canais com finalidades exclusivamente educativas;

III - reserva de tempo mínimo, sem ônus para o Poder Público, pelos concessionários de canais comerciais (BRASIL, 1996, p.29-30).

Além do Art. 80 da LDB No 9394 de 1996, temos o decreto No 9.057 de 25 de Maio de 2017 que regulamenta e normatiza a EAD no Brasil, trazendo em seus capítulos disposições gerais, oferta de cursos na modalidade a distância na Educação Básica, oferta de cursos na modalidade a distância na Educação Superior, disposições finais e transitórias que trata do monitoramento das instituições que ofertam esse tipo de modalidade de ensino (BRASIL, 2017). 
Mesmo com a expansão da EAD, muitas pessoas não reconhecem a importância e legitimidade dessa modalidade de ensino, inferiorizando os cursos da mesma, muitas vezes por falta de conhecimento, colocando em cheque padrões de qualidade, valorização no campo de atuação depois de formado, certificação, falta de professores qualificados, entre tantos outros motivos para não ingressar nesse mundo educativo.

\section{Desafios no EAD}

Ao passo que a educação a distância foi tomando forma e além de tudo foi sendo incorporada a diversos meios tecnológicos, teve-se muitos desafios a serem enfrentados, como qualquer coisa em evolução. Uma delas gira em torno do ensino superior na modalidade à distância, que foi considerada uma estratégia de organismos internacionais para a mercantilização e privatização do ensino superior, bem como críticas em torno da utilização da EAD para pós-graduação e principalmente formação de professores para a educação básica (SEGENREICH, 2006).

Na pesquisa realizada por Segenreich (2006) das universidades EAD credenciadas, as IES públicas lideravam em 2002, e que a partir de 2004 as IES privadas lideraram. Afirma também que houve um crescimento nos cursos de graduação EAD só a partir de 2002, bem como a oferta de vagas e o decréscimo acentuado de ingressantes, ocasionando vagas ociosas.

A pesquisa feita por Paiva (et al, 2012), trata de como o ambiente virtual pode ser organizado, sendo um atrativo para ingressantes, principalmente em licenciatura, o uso de materiais didáticos nesse espaço de interação, o conjunto de elementos, tanto na arquitetura e no uso da sala de aula virtual, quanto na elaboração e na utilização de materiais didáticos no intuito de tornar o estudante autônomo e protagonista da sua jornada de estudo. A pesquisa ainda enfoca que para que a educação a distância tenha sucesso, ou simplesmente seja mais facilmente viabilizada, é necessário que tenha como subsídios materiais didáticos com linguagem e organização dos conteúdos, ambientes virtuais com ferramentas interativas, e medição pedagógica, que no caso é a tutoria, que é de suma importância nessa modalidade de ensino.

Com relação à tutoria, esse eixo tão importante da educação a distância, Gilberto (2014) nos traz uma reflexão acerca da formação profissional e a prática docentes nessa modalidade, tendo em vista a expansão de cursos e redes na virada do milênio, bem como o envolvimento da IES com a EAD na formação de professores, levando em consideração a dimensão pedagógica das tecnologias na educação a distância a pesquisa realizada expõe que professores e alunos possuem dificuldades no processo de comunicação a distância, e para RPI

Revista de Pesquisa Interdisciplinar, v. 4, e4004, 2019. 
suprir tal dificuldade é preciso encontros presenciais para atender as dúvidas e aprofundar as discussão em fóruns. O mesmo fala que a formação dos professores para EAD deve contemplar conhecimentos que abordem tecnologias e linguagens a elas associadas, bem como conhecimento da prática docente a distância. Quanto ao desenvolvimento profissional docente nos movimentos de ensinar e aprender a distancia, mesmo com o empenho dos docentes nesse processo de aprendizagem, existe dificuldade para o desenvolvimento de estratégias de ensino-aprendizagem, isso pode se dá na maioria das vezes pela formação apenas técnica oferecida pelas instituições em prol do conhecimento das tecnologias e de competências técnicas, deixando de lado a didática propriamente dita, de como se trabalhar nesse campo, exigindo o desenvolvimento de habilidades e comportamentos específicos.

De acordo com Santos ( 2017), o papel do tutor é orientar os estudantes para aprendizagem incentivando o estudo e a pesquisa, acompanhar as atividades realizadas pelos alunos, participar de discussão em fóruns para a solução de dúvidas, ajudar no planejamento dos trabalhos, fornecer feedback, ter consciência das múltiplas facetas que tenha a desempenhar para atingir a aprendizagem de seus tutorados, acompanhando sempre seus resultados.

\section{A importância da EAD na atualidade}

A educação a distância rompeu muitas barreiras ao longo do tempo, tornando-se uma modalidade de ensino muito procurada, desmistificando a ideia de uma educação pronta e de má qualidade, graças às tecnologias que subsidiam e dão todo o suporte para que ela aconteça em todos os níveis de ensino, isso que dizer que, com a inserção das TIC's em favor, com uso de diversas ferramentas, provocou o interesse e curiosidade, em virtude de uma prática pedagógica que se utiliza de animações, infográficos, vídeo aulas, ilustrações, e muita interatividade nos ambientes virtuais de aprendizagem (AVA), garantindo o processo de construção e desenvolvimento das competências e habilidades necessárias para uma aprendizagem significativa, em que os estudantes deve ter uma dedicação maior com os estudos (SILVA; SACRAMENTO, 2014).

De acordo com Martins (et al, 2017):

No ensino a distância além das mediações das tecnologias, há também a mediação entre o aluno e o tutor, este é o responsável pelo acompanhamento e orientações do aluno na sala virtual. O Professor tutor participa dos fóruns, corrige e motiva a frequência das atividades, alerta para o cumprimento dos prazos e acompanha as disciplinas não se esquecendo da afetividade, 
buscando estabelecer uma relação de respeito, compreensão e abertura ao diálogo. É importante que o tutor faça sempre elogios ao aprendiz, à sua responsabilidade, pontualidade e empenho.

Dessa maneira, mesmo separados por tempo e espaço há uma interação virtual na EAD entre alunos e tutores, combinando com os novos padrões de comportamento das pessoas no mundo atual, que ficou cada vez mais dinâmico. Afirma ainda, através de autores pesquisados que é um caminho para a globalização de uma educação de qualidade, sendo disponíveis para os diversos níveis de ensino, tornando -se um método de ensino mais completo e eficiente. Outro sim, a EAD ajuda pessoas que possuem dificuldade em freqüentar um curso presencial, seja ele qual for o motivo, garantindo o ingresso para um aprendizado em qualquer horário e lugar (MAURO et al, 2017).

\section{CONSIDERAÇÕES FINAIS}

Por meio deste trabalho é possível enfatizar as muitas contribuições que a Educação a Distância oferece ao processo de ensino/aprendizagem. Embasado pelas ideias de vários autores que propuseram tal assunto em seus trabalhos acadêmicos, destacando as infinitas possibilidades nessa área de ensino.

Os autores aqui elencados, bem como as bases legais exploradas para essa pesquisa, expõem de forma clara o percurso da modalidade EAD, e de uma forma geral, procuram estimular uma educação alicerçada ao uso de novas metodologias.

O foco da pesquisa em questão foi de uma forma sucinta expor que a Educação a Distancia que é uma forma legítima de aprendizado, sendo reconhecida no Brasil e no mundo inteiro, levando em conta que ela possui suas raízes implantadas há muito tempo, com o ensino por correspondência, sendo utilizado inicialmente como recurso para superação de deficiências educacionais e qualificação profissional e/ou aperfeiçoamento, até que ela se expandiu e tornou-se importantíssima para as demandas atuais, de acesso, de tempo, de condições sociais e distâncias.

\section{REFERÊNCIAS}

ANDRADE, Nóslem Motta de. A práxis em educação ambiental de egressos dos sistema público de ensino superior a distância no Norte dos Espírito Santo. 2018. 120 f. Dissertação (Mestrado em Ensino na Educação Básica). Universidade Federal do Espírito Santo, Centro 
Universitário Norte do Espírito Santo. São Mateus, 2018. Disponível em: < http://repositorio.ufes.br/bitstream/10/10600/1/tese_12459_86\%20-

N\%C3\%B3slen\%20Motta\%20de\%20Andrade.pdf > acesso em 23 jan. 2019.

BALBINOT, Amanda Bifano; BULEGON, Ana Marli; OLIVEIRA, Elaine Harada Teixeira de; BEHAR, Patricia Alejandra; PORTELLA, Vera Catarina Castiglia. A prática docente em educação a distância: o uso do modelo metodológico dos três momentos pedagógicos. CINTED-UFRGS/ Novas Tecnologias na Educação, V. 8, nº 3, dezembro 2010. Disponível em: < https://seer.ufrgs.br/renote/article/view/18108/10680 > acesso em 15 dez. 2018.

BRASIL. Decreto No 9057, de 25 de Maio de 2017. Lex: Regulamenta o art.80 da Lei n $^{\circ}$ 9.394, de 20 de dezembro de 1996, que estabelece as diretrizes e bases da educação nacional, Brasília, DF, 2017. Disponível em: < http://www.planalto.gov.br/ccivil_03/_Ato2015-

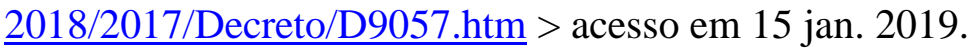

BRASIL. Lei No 9394, de 20 de dezembro de 1996. Lex: Lei de Diretrizes e Bases da educação Brasileira (LDB), Brasília, DF, 1996. Disponível em: < http://www.planalto.gov.br/ccivil_03/leis/L9394.htm > acesso em 15 jan. 2019.

ERCOLE, F. F.; MELO, L. S.; ALCOFORADO, C. L. G. C.. Revisão Integrativa versus Revisão Sistemática. REME - Revista Mineira de Enfermagem, V. 18, № 1, jan/mar 2014. Disponível em: < http://www.reme.org.br/artigo/detalhes/904 > acesso em 25 jan. 2019.

GILBERTO, Irene Jeanete Lemos. A formação profissional e a prática docente na educação a distância. Educação \& Linguagem, V. 17, nº 2, p. 91-104, jul.-dez. 2014. Disponível em: < https://www.metodista.br/revistas/revistas-ims/index.php/EL/article/viewFile/5333/4386 > acesso em 15 dez. 2018.

MARTINS, Evaneide Dourado; FELIX, Neudiane Moreira. Aluno Aprendiz em educação a distância: Material didático e avaliação. RPGE- Revista on line de Política e Gestão Educacional, $\quad$ v. 21, n. esp. 1, p. 799-813, out.2017. Disponível em: < https://periodicos.fclar.unesp.br/rpge/article/viewFile/9899/6811 > acesso em 15 jan. 2019. 
MAURO, Ricardo Arruda; FREITAS, Rodrigo Augusto de; CINTRÃO, Janaína Florinda Ferri; GALLO, Zildo. Educação a Distância: Contribuições da modalidade para uma qualificação empreendedora. Revista de Gestão e Projetos - GeP, V. 8, No 3, p. 118-128, Set/Dez $2017 . \quad$ Disponível em: http://www.revistagep.org/ojs/index.php/gep/article/view/572/pdf > acesso em 22 fev. 2019.

PAIVA, Fabrícia Vellasques; DIAZ, Mariane; GONÇALVES, Anne Caroline Silva. Prática de ensino e formação docente na EAD: Material didático e tutoria na construção da sala de aula de uma disciplina. In: SIED- Simpósio Internacional de Educação a Distância / EnPED - Encontro de Pesquisadores em Educação a Distância, 1a, 2012, São Carlos SP. Anais do I SIED; EnPED, UFSCar - Universidade Federal de São Carlos, 2012, p. 184. Disponível em: < http://sistemas3.sead.ufscar.br/ojs/index.php/sied/article/view/370/184 > acesso em 20 dez. 2018.

PIRES, Carla Simone; ARSAND, Daniel Ricardo. Análise da utilização das tecnologias da informação e comunicação na educação a distância (EAaD). Revista Thema, Pelotas/RS, V. 14, $\mathrm{n}^{\mathrm{o}} 1, \quad$ p. 182 a 198, 2017. Disponível em: < http://revistathema.ifsul.edu.br/index.php/thema/article/view/352 > acesso em 16 jan. de 2019.

ROSIN, Claudia Aparecida Bueno. A Educação a Distância no Brasil - Limites e possibilidades na implantação da EAD no Ensino Superior. 2010. 113 f. Dissertação (Mestrado em Educação) - UMSP/FEL - Universidade Metodista de São Paulo / Faculdade de Educação e Letras, São Bernardo do Campo 2010. Disponível em: < http://tede.metodista.br/jspui/bitstream/tede/1156/1/Claudia\%20Aparecida\%20.pdf> acesso em 25 jan. de 2019.

SANTOS, Ralph José Neves dos. O tutor presencial na educação à distância: Teoria versus prática no fazer docente nas instituições de ensino superior de Pirapora-Mg. Revista Multitexto, V. 5, $\mathrm{n}^{\mathrm{o}}$ 01, p. 87-96, 2017. Disponível em: < http://www.ead.unimontes.br/multitexto/index.php/rmcead/article/view/205 > acesso em 30 dez. 2018. 
SEGENREICH, Stella Cecilia Duarte. Desafios da educação à distância ao sistema de educação superior: novas reflexões sobre o papel da avaliação. Educar, Curitiba, no 28, p. 167-177, 2006. Disponível em: < http://www.scielo.br/pdf/er/n28/a11n28.pdf > acesso em 10 dez. 2018.

SILVA, Lucas Gomes; SACRAMENTO, Manuella Vieira. Educação a Distância: Impulso na cultura do ensino e da aprendizagem. Revista EaD \& Tecnologias Digitais na Educação, Dourados-MS, V. 2, $\quad \mathrm{n}^{\mathrm{o}} \quad$ 3, Jan./Nov. 2014. Disponível em: < http://ojs.ufgd.edu.br/index.php/ead/article/view/3963/2583 > acesso em 05 jan. 2019.

SOUZA, M. T.; SILVA, M. D. S.; CARVALHO, R. Revisão integrativa: o que é e como fazer. Einstein, 2010; $8(1 \quad \mathrm{Pt} \quad 1): 102-6 . \quad$ Disponível em: < http://www.scielo.br/pdf/eins/v8n1/pt_1679-4508-eins-8-1-0102> acesso em 25 jan. 2019. 